Vol. 70, N. ${ }^{\circ}$ III (mayo 20I8), I55-I7I

\title{
LA RENTA DEL CUERPO COMO FUENTE DE RIQUEZA DE LAS CELEBRIDADES. ESTUDIO DE CASO: LA ESTRELLA DE LA INDUSTRIA MUSICAL.
}

\author{
JON ILLESCAS MARTÍNEZ \\ Universidad de Alicante \\ Recepción de manuscrito: 19 de enero de 2018 \\ Aceptación versión final: 13 abril de 2018
}

\begin{abstract}
RESUMEN En la sociedad actual, dentro del conflicto distributivo entre capital y trabajo, identificamos un nuevo estrato de clase: los rentistas del cuerpo, popularmente conocidos como «celebridades». Ideológicamente, estos rentistas garantizan la hegemonía ganándose la admiración de las masas. Sin embargo, desde una perspectiva económica, su lugar es diferente. Son parásitos que renuevan su riqueza detrayendo parte del plusvalor generado por el obrero colectivo y realizado con la venta de las mercancías relacionadas con la industria cultural. Aquí explicaremos el origen de su poder - la renta del cuerpo-, basándonos en la renta del suelo expuesta por Marx y en el estudio de caso de la estrella musical.

PALABRAS CLAVE Renta del cuerpo, industria cultural, celebridades, teoría del valor-trabajo, marxismo.
\end{abstract}

ABSTRACT In today's society, within the distributive conflict between capital and work, a new class stratum has emerged, the rentiers of the body, popularly known as 'celebrities'. Ideologically, these rentiers promote the hegemony that earns the admiration of the masses. However, from an economic perspective, their place is different. They are parasites that extend their wealth by shifting a part of the surplus value generated by the collective worker with the sale of merchandise linked to the cultural industry. Here we will explain the origin of their social power: the body rent. To do so, we will develop the concept taking as basis the theory of ground rent exposed by Marx as well as a case study of music celebrities.

KEYWORDS Body rent, cultural industry, celebrities, labour theory of value, Marxism.

Jel Codes B51, D31, D46, L82, M32, M37, O34, P14, P16, Z1, Z13.

\section{INTRODUCCIÓN}

En el presente artículo observaremos cómo dentro del conflicto distributivo entre capital y trabajo que se produce en nuestra sociedad-mundo (Morin, 2005), hay un nuevo estrato de clase compuesto por lo que hemos denominado como rentistas del cuerpo, popularmente conocidos como «famosos» o celebridades, que sirven a los objetivos de acumulación del capital a través de su incesante reproducción en la industria cultural. Desde un punto de vista 
ideológico, estos rentistas garantizan la hegemonía burguesa ganándose la admiración de las masas (Gramsci, 2000 e Illescas, 2014 y 2016). Sin embargo, desde el análisis económico, su lugar es sustancialmente diferente. Aunque imprescindibles para la rentabilidad de la industria cultural en su conjunto, en realidad actúan como parásitos que renuevan su riqueza extrayendo una parte del plusvalor generado por el obrero colectivo y realizado con la venta de las mercancías propiedad de los capitalistas que invierten en la industria cultural -o en otras relacionadas-. En este artículo trataremos la naturaleza puramente económica de los rentistas del cuerpo en el modo de producción capitalista, pese a que en la realidad su funcionalidad está entrelazada con el componente ideológico (Illescas, 2016). Aislaremos la primera función de la segunda para facilitar el análisis y la exposición en las dimensiones del artículo.

Para entender el origen y el funcionamiento de este estrato de la clase rentista y, sobre todo, evitar confundir su fuente de riqueza con ningún tipo de salario - que a simple vista pareciera su forma fetichizada-, expondremos la fuente de la cual emana su poder social: la renta del cuerpo. Desarrollaremos el concepto basándonos en la renta del suelo explicada por Marx en el libro III de El capital (2010), en algunas observaciones del llamado Sexto Inédito (2009) y en anotaciones de autores marxistas contemporáneos adscritos a la Teoría del Valor-Trabajo (TVT) como Guerrero (1990 y 2009a), Husson (2007), Astarita (2009) y Arrizabalo (2014).

Preguntándonos por su génesis, es necesario comprender que los famosos lo son porque los registros - mediante imágenes y/o sonidos principalmente - de su realidad, se reproducen mecánica e insistentemente en el imaginario colectivo, lo que en otro lugar se denominó como iconosfera-mundo. ${ }^{1}$ Mediante su reiterativa aparición en las diferentes industrias culturales -industria musical, cinematográfica, literaria, publicitaria, medios de comunicación, etc.- (UNESCO, 2010 e Illescas, 2016), sus registros se hacen reconocibles para las mayorías de una sociedad global interconectada por el mercado mundial, los flujos transnacionales de capital y el uso cada vez más popularizado de internet.

Las estrellas de la industria cultural o celebrities pueden ser cantantes de música pop - como Katy Perry, Justin Bieber o Rihanna-, actores de Hollywood — como Vin Diesel, Megan Fox o Leonardo DiCaprio-, ases del deporte - como Cristiano Ronaldo, Lionel Messi o LeBron James-, etc.; pero lo que tienen en común es que deben la fama a su presencia icónica en las omnipresentes pantallas y altavoces que emiten contenidos de la industria cultural por todo el orbe. Este sector cultural está mayoritariamente controlado por el gran capital y su oligarquía mediática (Illescas, 2016). Sin esa base material, las celebridades perderían su condición social.

En ocasiones, los famosos también pueden ser empresarios — como Bill Gates o Carlos Slim—, líderes políticos — como los presidentes de Estados Unidos- o populares escritores - como Paulo Coelho, J. K. Rowling o E. L. James-, pero son una minoría respecto a los anteriores. Estadísticamente, las celebridades más populares internacionalmente, como se puede comprobar de un análisis de las principales redes sociales, son, sin duda, las estrellas de la música (Illescas, 2014 y 2016). En Twitter, más del 50\% del Top 100 son estrellas de la música, multiplicando por 9 a los ases del deporte o las estrellas de Hollywood. ${ }^{2}$ Por esa razón, expondremos la renta del cuerpo con el estudio de caso de la estrella musical. 
¿POR QUÉ LAS ESTRELLAS SON TAN RICAS? EL CASO DE LA ESTRELLA MUSICAL

Para lograr la fama, en especial entre la juventud, aunque también se sirven de otros medios más clásicos como la radio o la televisión, los cantantes utilizan como herramienta principal el videoclip y las redes sociales en internet. Ambos son poderosos reproductores masivos de su imagen y su voz, en definitiva: de su marca. En este sentido, hay que recordar que el videoclip dominante es el producto/mercancía cultural más consumido por la juventud global por encima de películas, series, videojuegos, libros, etc. -.${ }^{3}$ Celebridades como Selena Gómez, Lady Gaga, Shakira, etc., no serían tan famosas sin videos musicales que superasen los cientos — cuando no los miles - de millones de visualizaciones en YouTube. Su manufacturada fama se la deben, por completo, al conjunto de la industria cultural (Horkheimer y Adorno, 2009).

Cuando las estrellas comienzan su carrera en la industria musical, son trabajadores relativamente anónimos de bajos ingresos que han de vender su fuerza de trabajo para ganarse la vida. Como el valor del producto que generan - la actuación, el máster, el videoclip, etc. - es superior al que reciben a cambio - como le ocurre a cualquier asalariado del capital por tiempo o por pieza-, el plusvalor va a parar a los empresarios que tienen los medios de producción salas, estudios, redes de distribución, etc.- - Sin embargo, una vez alcanzada su condición de estrella, sus ingresos son desproporcionadamente más altos que los que recibe cualquier otro asalariado de la industria por muy complejo que sea su trabajo (Marx, 2010, pp. 54-55).

Normalmente, ejercen como músicos de profesión, aunque la mayoría solo como cantantes. Trabajan conjuntamente con asalariados «no estrellas» en la producción de sus álbumes y videoclips como: ingenieros, fotógrafos, camarógrafos, maquilladores, diseñadores, iluminadores, etc. (Schwartz, 2007, pp. 218-221). Sin embargo, cuando llegan a ser famosos, no lo son por su condición de músicos, sino por el tamaño del capital que hay detrás garantizando la costosa reproducción de su particular fuerza de trabajo y la marca adosada a ella. El gran capital sirve para pagar videoclips, payolas, pay for display, bufetes de abogados, asesores, preparadores físicos, profesionales del marketing online, grandes estudios, conseguir entrevistas en prime time o establecer contactos sincronizados que licencian su presencia en radio, televisión, publicidad, cine, videojuegos y un largo etcétera. ${ }^{4}$

Aun así, las estrellas siguen siendo asalariadas de las industrias culturales hegemónicas pese a que, legalmente, pudieran establecer diversas formas jurídicas de relación contractual como los llamados contratos de $360^{\circ}$ (Illescas, 2016, p.132). Son asalariadas del capital discográfico porque no tienen los medios necesarios para producir su estatus de estrellas del pop. Pudieran tener los medios de producción para ser músicos: su propia voz, algún instrumento, etc.; pero con ellos solo podrían ser productores independientes que vendieran su mercancía - su actuación - en la calle o a algún ayuntamiento o pequeño negocio (Marx, 2009, p. 84). Su ámbito de actuación quedaría muy restringido y en ningún caso serían mundialmente —ni siquiera nacionalmente- (re)conocidos.

Cada intérprete de la música pop, dependiendo de su caché, oscilará entre ser un trabajador asalariado, como es caso de un artista poco conocido por el que la discográfica todavía no ha decidido invertir el suficiente capital para transformarlo en estrella, a ser un trabajador asalariado que también es rentista, en el caso de aquel que ya ha sido convertido en celebridad. Mientras el primero suele padecer una situación laboral precaria con mínimas retribuciones 
por los pagos de regalías ${ }^{5}$ y sin cobertura sanitaria ni derechos de jubilación de calidad; ${ }^{6}$ el segundo logra la riqueza. Para llegar a la condición de celebridad, el candidato necesita una gran inversión que financie las ingentes campañas de marketing que garantizan su condición de estrella. La patronal calcula que para irrumpir en la escena de masas se necesita de una inversión mínima entre los USD 750.000 y los USD 1.400.000 (IFPI, 2012, p. 11). No hablemos ya de las cantidades necesarias para mantenerse en esa misma escena.

Sin estar dentro de los conglomerados multimedia - con múltiples industrias culturales de su propiedad como periódicos, revistas, canales de televisión, agencias de anuncios, compañías de videojuegos, etc. - que son propietarias de las grandes discográficas - Universal Music como parte del gigante mediático francés Vivendi, Sony Music dentro del japonés Sony Corporation o Warner Music en el estadounidense Access Industries_, las estrellas no aparecerían del mismo modo en los programas de televisión, ni en las revistas del corazón, ni en los anuncios publicitarios de las principales marcas. Sus canciones tampoco sonarían en los videojuegos de moda ni en los hilos musicales de los comercios de toda la geografía mundial ni sus vídeos serían insistentemente promocionados hasta lograr que fuesen los más vistos

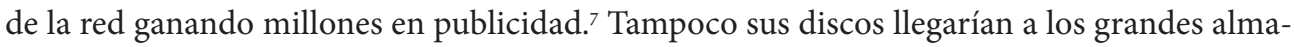
cenes que todavía venden música en formato «físico» - CD, DVD, etc. - ni a los espacios privilegiados de pay for display de tiendas online como iTunes. Y como suma de todo ello: sus giras internacionales no generarían millones de dólares. No en vano, las citadas tres discográficas más importantes - llamadas The Big Three - controlan el 88,53\% de las ventas en el mercado, el 92,4\% de los 500 videoclips más vistos en YouTube y el $95 \%$ de las redes de distribución (Illescas, 2016, pp. 138 y 387).

La particularidad de la estrella de la música, como la del as del deporte o la celebridad del cine, en tanto famosos de la industria cultural, estriba en que llegado determinado nivel de éxito consigue una remuneración que mayoritariamente proviene de otras fuentes que no son las del salario - directo o indirecto- de la discográfica/el club/la productora de cine. Si alcanza fama suficiente, puede recibir cuantiosas rentas a cambio de prestar su marca para la muy productiva industria publicitaria (Guerrero, 1990, pp. 124-125) o a toda una serie de productos de merchandising como libros, juguetes, videojuegos, perfumes, prendas, etc. Se produce así una transformación cualitativa en su clase social, y aunque técnicamente sigue ocupando el lugar de fuerza de trabajo - pues todavía debe cantar para otros que invierten el capital por un ingreso no equivalente al valor producido-; ahora, por la fuente de sus ingresos mayoritarios, hemos de caracterizarlo como un trabajador que también se transformó en rentista. ${ }^{8}$ ¿Pero rentista en base a la propiedad de qué? Al monopolio sobre su cuerpo y los derechos de cobro de regalías - derechos de autor como compositor, de voz, de imagen, de escritura, etc. - que del mismo se deriven por la utilización de registros reconocidos como «suyos» en la producción de otras mercancías de las cuales él no es dueño.

Estos registros pueden ser visuales - fotografías o logos-, sonoros - canciones, discursos, etc. - , audiovisuales — videoclips, publicidad, etc. - e incluso sígnicos o literarios —un escritor de éxito también sería rentista del cuerpo-. Sobre estos registros, que formarán parte de otras mercancías, la estrella conservará derechos en tanto reconocido propietario de su organismo, en tanto rentista del cuerpo. ${ }^{9}$ Expongamos ahora la definición de la renta corporal 
como el ingreso que percibe un sujeto en base a su derecho legal para adueñarse de parte de las ganancias obtenidas por la venta de mercancías que, sin ser de su propiedad, utilizan registros públicamente reconocidos de su organismo.

La clave radica en que la estrella, a diferencia de otros asalariados, no enajena toda la mercancía que produce, sino que una parte — relacionada con su marca—, la «cristaliza» en su propio cuerpo por semejanza icónica. Por ejemplo: aunque la grabación de la canción es propiedad de la discográfica - el master - la celebridad conserva la fama adosada a la necesaria publicidad de su nombre, su voz y su imagen. Y el reconocimiento de su marca en la sociedad-mundo, se consigue invirtiendo el tiempo de trabajo socialmente necesario (TTSN) de miles de asalariados que forman la cadena del valor de las mercancías asociadas sígnicamente a su nombre.

Este reconocimiento se produce por el nivel de semejanza o iconicidad que las expresiones o manifestaciones reales del cuerpo del artista tienen con respecto a los registros de los mismos industrialmente (re)producidos por la industria cultural — su voz con respecto a los sonidos que representan su voz grabada, su cuerpo con la imagen del mismo reproducida fotográfica o audiovisualmente, etc.- - Esta iconicidad permite a los artistas reclamar unas rentas en base a la propiedad del organismo que las generó: el suyo. Así, el TTsN que los asalariados anónimos emplean para que la discográfica consiga hacer del artista de su repertorio una marca global, también sirve para aumentar el margen de negociación del propio artista al empoderarlo como propietario de su marca-mercancía, lo que le reporta más beneficios que el valor equivalente a la simple reproducción de su fuerza de trabajo.

Los citados registros alimentan su marca global: su presencia simbólica y socialmente reconocible en la iconosfera-mundo. Mientras que la propiedad de ésta, que posee gracias a hecho de que la superestructura jurídica actual reconoce los derechos de autor y de imagen (García Aristegui, 2014), es la garantía de reconocimiento para la industria que invierte en el músico transformado en estrella. De este modo, toda empresa que produzca alguna mercancía basada en la presencia simbólica del artista, en el monopolio legal que el cantante tiene sobre la materialidad de su organismo y los registros y/o representaciones que de él se deriven, habrá de destinar una parte de las ganancias a retribuir por el uso de este derecho.

Veamos cómo opera este tipo de renta con un ejemplo real. En 2016, apareció el nuevo perfume oficial de Shakira, llamado «Dance», dirigido al público femenino y producido por la multinacional española de moda y fragancias Puig (Garbulsky, 2016). A este perfume había que sumarle otros dos que la cantante ya tenía en el mercado llamados «Elixir» $\mathrm{y}$ «Rock!», producidos por la misma empresa afincada en Cataluña. Pues bien, Puig, en tanto compañía productora, detrajo de las ganancias de los tres perfumes una parte que en forma de renta cobraron tanto la ciudadana de Bahamas de origen colombiano afincada en Barcelona, Shakira Isabel Mebarak Ripoll, como su compañía discográfica - Sony - en concepto de derechos de imagen. ${ }^{10}$

De este modo, la cantante pudo reclamar un derecho de cobro sobre las plusganancias generadas por una mercancía que ella no ha producido, ni como capitalista ni como fuerza de trabajo - el perfume- $-{ }^{11}$ Además, puede participar de la realización de las plusvalías contenidas en cada uno de esos tres perfumes gracias al monopolio reconocido por ley que tiene sobre sus derechos de imagen, lo que le ha permitido incorporar un enorme valor sobre la marca-mercancía que es ese conjunto de caracteres que forman su símbolo: «Shakira». Así, 
ese mismo año fiscal, Puig debió entregar una parte de sus 1645 millones de euros en ventas a varios de los famosos que le ayudaron a apuntalar su negocio con perfumes oficiales: como la citada cantante o el actor Antonio Banderas (Lamelas, 2017). Cinco años antes, en 2011, se calcula que las celebridades aportaron a la industria de perfumes unos USD 130.000 millones —solo en Estados Unidos-. Un 25\% del total de la industria (Sherwin, 2014).

Este derecho a cobrar rentas del cuerpo legalmente reconocido se basa a su vez en otro derecho burgués: el derecho de la libertad y la propiedad monopolista individual de los sujetos productores sobre sus cuerpos. Este reconocimiento legal es un avance histórico específico derivado del modo de producción capitalista que necesita de sujetos «libres» que puedan vender su fuerza de trabajo en el mercado. La renta del cuerpo o renta genética no podía existir en ningún modo de producción precapitalista, donde no fuera reconocida jurídicamente la libertad de los individuos productores por ser: 1) súbditos de la élite burocrática que gobernaba despóticamente el conjunto social — modo de producción asiático o despotismo comunal-, 2) propiedad de otros - esclavismo - o 3) vasallos de los miembros de la clase dirigente - feudalismo—-. ${ }^{12}$ La misma «libertad» que permite la renta corporal a la estrella de la industria cultural es la que posibilita que el asalariado «común» pueda vender su fuerza de trabajo al empresario individual que quiera, pero le obliga a hacerlo siempre con la única clase que la puede comprar. Su libertad es parcial: es libre en tanto que individuo pero «esclavo» en tanto individuo de una clase explotada en el proceso productivo. Sumado a ello, la renta del cuerpo implica un determinado desarrollo de las fuerzas productivas pues no podía existir de un modo significativo antes de la invención de la imprenta moderna, la extensión del mercado mundial, la popularización de los ordenadores, la tecnología móvil satelital o internet. Se necesita de una comunidad global lo suficientemente numerosa, solvente y conectada de cara al mercado como para hacer rentable un negocio basado en el reconocimiento y la conquista emocional de las masas - la fama-.

Para entender mejor el concepto de renta diferencial corporal - su nombre técnico completo- es necesario atender al concepto de renta diferencial asociado al de renta del suelo, explicado por Marx en el libro III de El capital (Marx, 2010). Allí caracteriza la apropiación que los terratenientes efectúan de parte de las ganancias percibidas por los capitalistas en base a la producción de plusvalor en sus terrenos. Para comprender la fuente de ingresos de la celebridad, deberemos atender a la renta diferencial corporal sin olvidar que en un mismo sujeto pueden convivir realidades diferentes. Es posible que siga siendo asalariado e incluso que pueda convertirse en un pequeño o mediano empresario de otras ramas de la producción - como hostelería, ocio nocturno, empresas textiles, etc.-, pero en todo caso, llegado a la categoría de estrella será, sobre todo, un rentista. Pues de esta condición recibirá la mayor parte de sus ingresos. Analicemos cómo.

\section{LA RENTA DE LA TIERRA DE KARL MARX}

Marx trata la transformación de la plusganancia en la renta de la tierra en la sección vi del libro III de El capital (Marx, 2010, pp. 791-1034). Para entender la renta de la tierra en Marx, el punto de partida es el de los arrendatarios capitalistas de los terrenos agrícolas. Éstos arriendan 
la tierra a los propietarios - usualmente terratenientes - por el pago de una renta y se comportan como grandes fabricantes industriales: compiten entre sí, transfieren su capital de unos sectores a otros, buscan la ganancia media, etc. Así «una parte del plusvalor generado por el capital cae en poder del terrateniente» (Marx, 2010, p. 791). Pero los propietarios de la tierra solo pueden recibir esta renta allí donde hay una sociedad capitalista lo suficientemente desarrollada, pues presupone el monopolio de ciertas personas sobre determinadas porciones del planeta. La renta es la forma en que se valoriza su propiedad en el mercado, lo que el arrendatario paga al propietario de la tierra por su uso productivo.

Pero la tierra, como el agua o el viento, no son fruto del trabajo humano abstractamente indiferenciado y, por tanto, no tienen valor — trabajo socialmente necesario (TSN) - ni magnitud del valor - tiempo de trabajo socialmente necesario (TTSN) - . Todos estos recursos no emanan ni del trabajo humano ni de su conjunción con el capital, son por el contrario producto de las fuerzas de la naturaleza. Eso sí, para servir como instrumento gratuito al proceso de valorización de otras mercancías con auténtico precio de producción debe ser monopolizadas por individuos que puedan interactuar en el mercado como sus propietarios legítimos.

Siguiendo a Ricardo, Marx afirma que «la renta es siempre la diferencia entre el producto obtenido mediante el empleo de dos cantidades iguales de capital y trabajo», aunque, agrega: «en una misma cantidad de terreno» (Guerrero, 2009b, p. 206). La diferencia es la calidad específica de la fuerza natural monopolizable, privatizable, expropiable al conjunto social. Por ello, las diferencias en el rendimiento, lo que nos transporta a la renta diferencial 1 de Marx. Según este tipo de renta, debido a la disímil calidad natural de cada tipo de suelo, las rentas serán también diferentes. Es decir, no rendirá igual una tierra más fértil que otra menos. Marx también señala cómo el precio del suelo no cultivado está determinado por el precio de las tierras cultivadas de la misma calidad y ubicación, además de que el avance hacia suelos de peor calidad solo puede resultar de un aumento general del precio de los ya explotados. Por su parte, la renta diferencial 2 comprende el hecho de que frente a dos terrenos de igual calidad, obtendrá un mayor rendimiento aquel en el que se invierta un capital mayor. Es decir, que Marx se refiere desde su siglo XIX a la diferencia entre la agricultura extensiva y la agricultura intensiva. La última de ellas como la específicamente capitalista, la cual eclosionaría mundialmente con la Revolución Verde a mediados del siglo xx.

La renta del suelo del economista de Tréveris afincado en Londres, no solo atañe a los terrenos agrícolas, sino a la renta minera o a los solares urbanos. En todo lugar donde las fuerzas naturales sean monopolizables y garanticen a los capitalistas plusganancias, tendremos rasgos comunes como 1) la «total pasividad» del propietario - siempre que no aúne las figuras del terrateniente y del capitalista-, 2) el predominio del precio monopolista — relacionado con «la renta absoluta»—, 3) la «desvergonzada explotación de la miseria» —refiriéndose, por ejemplo, a los alquileres urbanos- y 4) el poder descomunal que confiere cuando la propiedad de la tierra está en las mismas manos que el capital industrial, pues de este modo una parte de la sociedad - la capitalista-terrateniente - podrá reclamar un tributo a los productores - la clase trabajadora- a cambio «del derecho a habitar la tierra».

En síntesis, la renta del suelo de Marx es el derecho a detraer una parte de los beneficios de la actividad productiva capitalista que pesa sobre los productores en base a la posibilidad 
legal que tienen algunos individuos de monopolizar diversos recursos naturales. Haciéndolo, los transforman mercancías privadamente explotables para la actividad económica. Así el propietario que ha usurpado una parte de la Naturaleza a la colectividad, según Marx, está quebrando su derecho natural de usufructuario por un derecho propio de una sociedad de clases como la capitalista. En realidad, esta privatización de la tierra es la «premisa histórica [...] [y] el fundamento permanente del modo capitalista de producción, así como de todos los modos de producción anteriores que se basan en la explotación de las masas de una u otra forma» (Marx, 2009, p. 794). La renta del suelo, por tanto, no existiría en una sociedad socialista o comunista - futura o primitiva - donde ningún individuo fuera propietario de los medios de producción naturales. Tampoco la renta del cuerpo, como veremos a continuación.

\section{CELEBRIDADES Y TERRATENIENTES, LEJANOS PRIMOS HERMANOS}

La renta del cuerpo en tanto herencia genética titularizada - por eso, también la llamamos renta genética-, no mediada por el trabajo humano, tiene diversos paralelismos con la renta de la tierra de Karl Marx. Para comenzar, la herencia genética de cada cual, al igual que un trozo de tierra o un río no modificados por la acción humana no poseen valor - económicoporque no han sido producidos por el trabajo humano y por ende no contienen ni un segundo de TTSN (Marx, 2010, p. 48 y pp. 823-833). La naturaleza los legó al ser humano sin intermediación de su actividad consciente. De la misma forma que el terrateniente no creó la tierra que posee gracias al derecho de propiedad privada del suelo que la ley reconoce, la celebridad, como rentista, tampoco creó la estructura genética que le fue legada por la naturaleza: no produjo su altura, el color de sus ojos, la forma de sus curvas ni el timbre de su voz. Sin embargo, la ley actual le garantiza su propiedad jurídica.

Sin duda, en la formación de la fuerza de trabajo, además de la herencia genética — natural- y el TTSN invertido en su formación, también afectan los condicionamientos ambientales y sociales que rodeen al sujeto: como el medio ambiente, el clima, la zona donde habite según la división internacional del trabajo, la clase social, la educación, el poder adquisitivo y las cosmovisiones e ideologías que sus padres posean, etc. Todos estos condicionamientos heredados marcarán los procesos de sociabilización del individuo, le legarán, como sostenía Bourdieu (2001), un capital cultural — formación cultural - y social — contactos - que el sujeto irá incorporando desde los primeros años de la infancia (pp. 135-136). Capitales no económicos que sin duda afectarán al valor —económico — de su fuerza de trabajo adulta. ${ }^{13}$ Pero para simplificar la exposición, los obviaremos centrándonos en la dialéctica entre la herencia genética y el TTSN gastado por el individuo para su formación laboral.

La herencia genética que precede a la renta del cuerpo, pero difiere de ella, opera en todo momento a la hora de contratar y establecer las remuneraciones de los trabajadores, más allá de los diferentes tiempos invertidos para su formación. Estos últimos, verificados por el mercado, definirán si el trabajo es simple o complejo (Astarita, 2014), pero la herencia genética modificará al alza o a la baja la capacidad de cada individuo para lograr las mismas capacidades - fuerza de trabajo- con mayor o menor gasto de tiempo y esfuerzo, en relación a la media socialmente necesaria. La diferencia estriba en que, dependiendo de la rama industrial, 
la herencia genética adquirirá una importancia fundamental o se minimizará hasta prácticamente no incidir en la contratación, el salario o la promoción laboral. ${ }^{14}$

Por ejemplo, la herencia genética no tendrá prácticamente relevancia en la contratación de un obrero de una cadena de montaje - porque se acercará más al trabajo simple y el aspecto físico del asalariado, por estar oculto dentro de la fábrica a los ojos de los consumidores, no tendrá relevancia en las ventas-, pero sí afectará en la contratación de una camarera de una discoteca de moda o una astronauta de la NASA. En el caso de la primera, la herencia genética - exterior - será fundamental para que su atractivo naturalmente heredado atraiga a los clientes y ayude a aumentar las ventas. ${ }^{15}$ En el caso de la segunda, debido a que su inteligencia natural - herencia genética interior- deberá estar muy por encima de la media por la complejidad del trabajo a realizar y los altos requerimientos de formación - miles de horas de vuelo, licenciaturas o doctorados en ingenierías, etc. - y porque estará obligada a tener una salud física envidiable, sin enfermedades de ningún tipo ni defectos en la visión (NASA, 2014). En el caso de la industria musical y el videoclip dominante, la herencia genética exterior será fundamental para poder transformarla en renta del cuerpo. Obsérvese este esquema (ver Figura 1) que sintetiza parte de lo visto hasta el momento.

Sin una herencia genética exterior e interior mínima, el músico no se transformará en un rentista. Sin embargo, lo que transforma a los músicos asalariados en rentistas del cuerpo es la decisión de la discográfica de invertir un capital suficiente para convertirlos en celebridades de la música global. Aunque la herencia genética es necesaria, solo puede transformarse en renta corporal gracias a que la oligarquía mediática haya decidido invertir previamente en estos sujetos propietarios de una cualificada herencia. Lo cual es una decisión política, de economía política, para ser exactos, ${ }^{16}$ como se en este esquema (ver Figura 2).

La oligarquía mediática de magnates y altos ejecutivos invierte un capital suficiente en unos músicos asalariados escogidos entre todo el repertorio de la discográfica multinacional hasta que los convierten en estrellas de la música — rentistas del cuerpo de la industria cultural-. Una vez convertidos en estrellas cobrarán unas rentas corporales que provendrán de las plusganancias que las empresas que inviertan en ellos logren frente a la competencia de capitalistas musicales que invierten el mismo dinero en cantantes no estrellas. Por otra parte, cuanto mayor sea la sintonía personal e ideológica de estas nuevas celebridades de la industria musical con la oligarquía mediática de la que depende su condición de celebridad, mayor será su estrellato y su nivel de ingresos.

Otra característica común entre la renta diferencial corporal y la renta diferencial de la tierra estudiada por Marx viene de su carácter «diferencial». La misma inversión de capital en diferentes cuerpos/tierras produce diferentes rendimientos según la «calidad» de la herencia genética, de la naturaleza heredada desde la que cada individuo parte — renta diferencial 1-. Pongamos un ejemplo. Imaginemos como postulantes a estrella de la música a una joven artista llamada Nataly con una gran voz, un rostro precioso y un cuerpo exuberante y, por otro lado, a otra llamada Laura con una gran voz, pero con un rostro en la media y un cuerpo poco atractivo según los cánones vigentes. Es evidente que el empresario dedicado al negocio musical escogerá a Nataly para invertir en ella. ${ }^{17}$ La preferirá en base a su herencia genética, ya que con la misma inversión los rendimientos serán muy superiores apostando por Nataly que por 
Laura. Su mayor atractivo natural — proporciones esqueléticas, disposición de la grasa en las distintas zonas del cuerpo, calidad y elasticidad de la voz, etc. - la hará más productiva para seducir al público y venderle las mercancías asociadas — discos, videoclips, conciertos, merchandising, spots de otras empresas exomusicales, etc.-. ${ }^{18}$

Un tercer aspecto coincidente con la renta de la tierra es que la del cuerpo se basa también en la monopolización de una fuerza productiva natural y esto es parte del desarrollo histórico del Homo sapiens. Del mismo modo que la renta de la tierra presupone la monopolización privada de determinados bienes naturales que en el comunismo primitivo no eran propiedad de ningún sujeto ni grupo de personas, la renta del cuerpo presupone la existencia de un sujeto «libre» dueño de la mayor parte de su propio organismo. ${ }^{19}$

Solo resta mencionar el cuarto y último aspecto donde la renta de la tierra de Marx coincide con la renta diferencial corporal que proponemos. Al igual que en aquella existen dos tipos. La primera se basa, como ya vimos, en la disímil fertilidad natural del suelo - o del cuerpo- y la segunda en «las diferencias en la distribución del capital - y de capacidad de crédito-» de los inversores capitalistas (Marx, 2010, 867-869). Evidentemente, la inversión en una cantante con una gran voz, con enorme atractivo y carisma por parte de una pequeña discográfica independiente obtendría un volumen total y relativo de ganancias muy inferior a si una major como Universal Music invirtiera en la misma cantante con un capital y crédito mucho mayores.

Resumiendo hasta lo expuesto: la razón por la cual la retribución de celebridad de la industria cultural es tan alta hay que buscarla en la renta del cuerpo. Su aparente salario es una forma fetichizada de renta. Porque el TTSN que cuesta reproducir su marca no es solamente el que la estrella - musical, cinematográfica, deportiva, etc. - ha aportado para la reproducción de su fuerza de trabajo, sino porque, por semejanza icónica, su cuerpo/marca lleva objetivado la labor de miles de obreros que trabajan diariamente para que su imagen sea reconocida allende las fronteras (Passman, 2012, pp. 63-64).

¿Qué sería de un perfume con el nombre de Shakira sin su marca? Una mercancía que no se vendería igual pese a que su fragancia fuese exactamente la misma. La marca «Shakira» agrega valor al producto al contener el TTSN objetivado en la imagen-marca «Shakira» que, reproducida mecánicamente por el conjunto de la industria cultural en diversas mercancías, transfiere valor a cada perfume. Por esa razón, los empresarios que invierten en la producción del perfume pagan en concepto de derechos de imagen a la discográfica y a la artista por unas plusganancias que no obtendrían si el mismo producto no llevara adosada la marca de la célebre cantante. ${ }^{20}$ La marca «Shakira» pasa entonces a ser parte del capital constante de otras mercancías, como maquinaria que transfiere su valor (Marx, 2010, p.191).

Precisamente por vulnerar el derecho a cobrar la renta corporal, en 2013, la cantante Rihanna demandó por USD 5 millones a la multinacional inglesa Topshop. Esta empresa textil minorista comercializó un modelo de camiseta con una imagen de la cantante sin su consentimiento. Topshop había pagado al fotógrafo por el derecho a emplear la fotografía, pero en ningún momento a Rihanna. Al final, el juez falló a favor de la rentista del cuerpo barbadense que en esos momentos tenía un contrato de cesión de derechos de imagen con otra empresa de la competencia: River Island (Brant, 2013 y Robertson, 2013). 
Figura 1. Herencia genética y el nivel de remuneración de los trabajadores

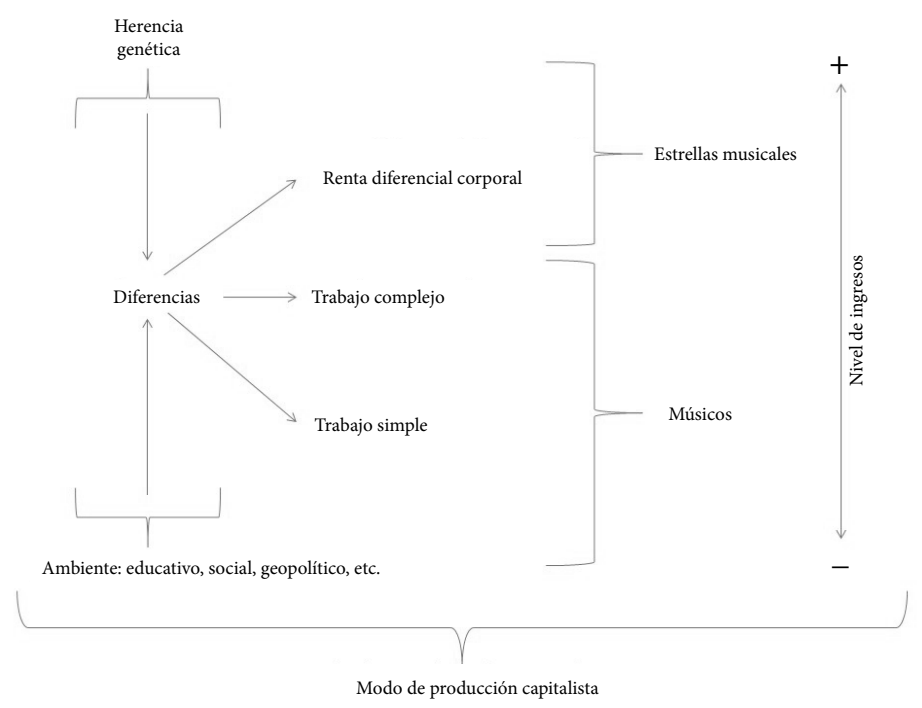

Fuente: elaboración propia.

Figura 2. Herencia genética, influencia de la oligarquía mediática y remuneración de trabajadores

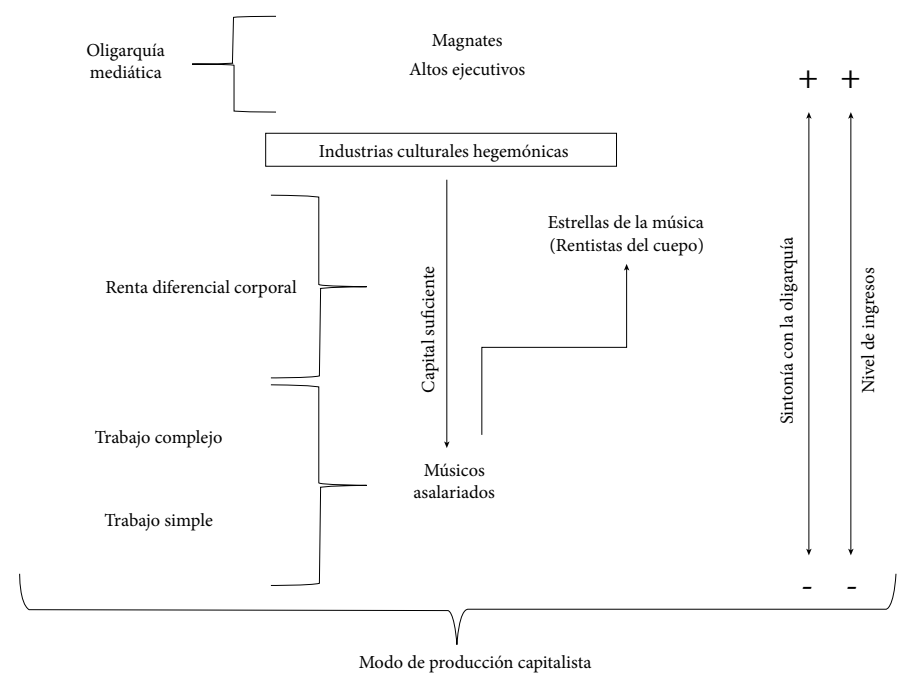

Fuente: Elaboración propia.

OBSOLESCENCIA NATURAL DE LA RENTA DEL CUERPO

Solo nos resta señalar la caducidad de este tipo de renta. Así, del mismo modo en que en el proceso global de producción capitalista los terrenos pierden fertilidad a medida que pasan los 
años - reduciéndose su valor relativo de cara a la actividad agrícola-, a la estrella de la música le sucede lo mismo con su cuerpo. A medida que envejece para la función de celebridad, como la tierra que se agota, tiende a desvalorizarse y, con este proceso, la proporción de rentas que puede acaparar de la clase capitalista tiende a decrecer pues, al fin y al cabo, su capacidad para capturarlas se sostenía en su actividad como trabajadora de la música.

Para seguir cobrando rentas corporales, a medida que envejecen, las estrellas de la música diversifican sus apariciones en los medios de comunicación participando en programas de televisión en calidad de comentaristas, jurados en concursos musicales u otras profesiones ajenas a las de cantante que les hizo famosas. De este modo, si sus cuerpos dejan de ser sexualmente atractivos - pese a las constantes operaciones de cirugía estética - o sus voces pierden vigor, seguirán capturando rentas desarrollando otro tipo de actividades dentro del espectáculo de la industria cultural y su marca reconfigurará su valor en relación a esta metamorfosis - normalmente a la baja-.

Sin embargo, la desvalorización que sufre el cantante a medida que envejece respecto a su capacidad para reclamar rentas de su labor en el presente, deja intacta su capacidad para reclamarlas de su labor pretérita. Gracias a la aprobación de la estadounidense Copyright Act de 1976 y a sus modificaciones posteriores, el artista podrá reclamar regalías por la venta y reproducción de sus canciones, videoclips, etc., hasta el día de su muerte, ${ }^{21}$ siempre que figure como compositor del tema. ${ }^{22} \mathrm{Y}$ al igual que sucede con las escrituras de una propiedad inmueble que permiten a su propietario reclamar la renta del suelo, estos derechos de titulación serán heredables por sus descendientes, al menos durante 70 años después del fallecimiento del cantante. Quizás en un futuro próximo lo sean tanto como aquéllas, a medida que los interesados presionen a los gobiernos para ampliar la ley.

Para finalizar, pensemos qué ocurriría con la desaparición de una estrella musical. Si sufriera un accidente mortal, la inversión de la discográfica correría riesgo de no rentabilizarse. Aunque al principio la compañía podría obtener súbitos beneficios con la edición de álbumes póstumos y durante un breve período tendría a los medios generando noticias de su trágica muerte, como sucedió recientemente con David Bowie, Prince o George Michael, siempre será mayor el valor que la discográfica pueda generar durante más tiempo en y con la estrella viva que con la estrella muerta. Si ha fallecido o está inhabilitada para cumplir con los requerimientos que la capacitan para ser estrella, el valor que se puede generar invirtiendo en su marca tiende a agotarse como un terreno sin humus para el cultivo, por mucho abono - capital- que se le eche. Por esa razón, numerosas celebridades musicales aseguran partes de su cuerpo como si fueran bienes inmuebles frente a cualquier posible eventualidad (Smith, 2015).

\section{CONCLUSIONES}

La renta del cuerpo se presenta como una propuesta inédita dentro del enfoque marxista de la economía política para explicar el origen de la riqueza de las celebridades de la industria cultural: los «famosos». El perfeccionamiento de la renta de la tierra por Marx en el siglo XIX nos alumbra una realidad económica desarrollada en el siglo xx con los medios de comunicación de masas y potenciada hasta límites insospechados en el siglo xxi con la creciente 
configuración de una sociedad-mundo interdependiente por el mercado mundial e interconectada por internet y la tecnología satelital. Así, la renta del cuerpo completa -a la vez que subraya-, con su análisis económico, la funcionalidad ideológica de las celebridades en el proceso global de acumulación ampliada de capital. Algo ya expuesto por otros autores, que caracterizan a los «famosos» como garantes de la reproducción de la hegemonía que garantiza el liderazgo político, cultural y moral de la clase capitalista sobre la trabajadora - sostenido por la industria cultural burguesa- - Las celebridades, con su estilo de vida procapitalista, serían ejemplos a seguir y admirar por la mayoría social. Sin embargo, la renta del cuerpo, además de subrayar esta realidad ideológico-cultural que por sí misma no explica, descubre y desmitifica el origen del aparente y extremadamente abultado «salario» que los famosos ganan basándose en la TVT. La renta del cuerpo demuestra así que el origen de esta riqueza no es debido a la «genial» diferencia entre los artistas y el resto de la humanidad asalariada — que tendría su justificación en la extremadamente desigual asignación de recursos-, sino que es social. La renta del cuerpo sería fruto exclusivo de lo que Marx denominó el obrero colectivo y, por ende, de la explotación capitalista de la mayor parte de la humanidad no propietaria de los medios de producción.

La presentación del concepto de renta del cuerpo puede ser la semilla que de lugar a nuevas investigaciones que tracen y vehiculen la conexión entre la funcionalidad ideológica y la económica de las celebridades de la industria cultural, apenas esbozada en este artículo por cuestiones de espacio. Al mismo tiempo, puede servir para presentar estudios de casos concretos donde se analice el cobro de la renta corporal a través de los llamados contratos de $360^{\circ}$ grados en la industria discográfica que cada vez más atan de pies y manos al artista en relación con la empresa que lo explota. Sin duda puede tener un valor fundamental para analizar la producción de la industria publicitaria — otra industria cultural más, como la musical o la cinematográfica- y dentro de ésta para comparar las diferencias en la apropiación de plusvalor y plusganancias en relación con las empresas que no utilicen a las celebridades como reclamos para sus anuncios. Otra cuestión interesante sería analizar en qué medida el monto de la renta corporal cobrado por la celebridad de la música se halla en relación inversamente proporcional con su compromiso crítico o político en contra del orden establecido. También sería revelador conocer el rol que los rentistas del cuerpo han jugado o podrían jugar en periodos revolucionarios o bonapartistas, ¿junto a qué clase de las dos mayoritarias han luchado/ lucharían políticamente?, ¿con la capitalista que la nutre en los tiempos de normalidad o con la trabajadora que brega por establecer un nuevo orden poscapitalista donde la renta corporal podría ser abolida?

Éstas y otras muchas cuestiones podrían plantearse a partir de la exposición teórica de la renta del cuerpo demostrando una vez más que debido a la incesante profundización de la lógica capitalista en nuestra sociedad-mundo, la herencia teórica de Marx está más viva que nunca. Mucho más, sin duda, que cuando en 1894 vio la luz el tercer libro de la obra que terminó de editar su amigo, colaborador y eminente pensador Friedrich Engels. Inmensamente más ahora que las celebridades seguidas e idolatradas por cientos de millones de personas desde los diferentes aunque cada vez más semejantes países del sistema-mundo, se construyen con métodos específicamente capitalistas, dentro de una industria cultural gobernada por 
mano de hierro por la oligarquía mediática de esta clase burguesa. Marx es más necesario que nunca para entender nuestro mundo actual.

\section{NOTAS}

1 «La iconosfera-mundo es aquella parte de la iconosfera que es potencialmente conocida por la mayoría de habitantes del planeta». Mientras que la iconosfera es «la parte del conjunto de imágenes y sonidos que nos rodean y tenemos almacenados en nuestra cosmovisión» (Illescas, 2016, p. 206).

2 Las cien cuentas con más seguidores de Twitter en 2015, estaban copadas por las siguientes profesiones: $54 \%$ cantantes - estrellas del videoclip dominante-, $14 \%$ empresas, $6 \%$ ases del deporte, $6 \%$ actores de Hollywood, $4 \%$ presentadores de TV, $4 \%$ famosos sin profesión conocida, $2 \%$ para humoristas, políticos y clubs deportivos - R. Madrid y F. C. Barcelona- y 1\% para escritores, modelos, empresas públicas, empresarios y otros mixtos.

3 El videoclip es «es un cortometraje basado en el desarrollo de una composición musical previa que fundamenta el despliegue de un conjunto de imágenes, las cuales, unidas a la música, dan lugar a un nuevo discurso estético» (Illescas, 2016, p. 41), mientras que el videoclip mainstream o dominante es «aquel videoclip comercial producido y difundido por las industrias culturales hegemónicas con la intención de conquistar un público mayoritario dentro de una o varias franjas de edad en un territorio determinado, usualmente, de amplitud transnacional» (Illescas, 2016, p.42).

4 Dentro de los profesionales del cada vez más importante marketing online destacan figuras como el Social Media Managers, Community Managers, Consultores SEO y SEM, analistas digitales, creador de contenidos digitales, expertos en comercio electrónico, desarrolladores y posicionadores de aplicaciones móviles, etc.

5 El solista o grupo promedio gana solo USD 23,40 por cada 1000 discos vendidos y hay que recordar que solo un 2,1\% de los álbumes que salieron a la venta en 2009 pasaron de las 5000 unidades (Jefferson, 2010).

6 Nos referimos al caso de Estados Unidos, donde se concentran las principales empresas de la industria musical mundial (Kelley, 2002, pp. 329-332).

7 Uno de los videoclips más vistos, el Can’t remember to forget you de Shakira con la colaboración de Rihanna (Joseph Kahn, 2014) estuvo una semana de portada de YouTube. Pocas empresas podrían permitirse una campaña de pay for display tan cara. La explicación es que Google-YouTube son propietarias de una parte de Vevo que es el canal que publica el videoclip y que se llevará parte de las ganancias generadas por la publicidad adosada al metraje de Shakira y Rihanna.

8 En el capitalismo, un sujeto, dependiendo de la posición en la producción y el porcentaje de su fuente de ingreso, puede ocupar posiciones de clase híbridas como la estrella de la industria cultural. Es el caso típico de un pequeño propietario que emplea a un grupo reducido de trabajadores y por no ganar suficientes ganancias, no puede emanciparse de las labores productivas. En este caso, sigue laborando como fuerza de trabajo pese a que, probablemente — si el negocio le va bien —, la mayor parte de sus ingresos vendrán de las ganancias que obtenga como capitalista «explotándose» no solo a él mismo, sino al resto de asalariados «puros» que emplea (Marx, 2009).

9 Entendemos aquí el «cuerpo» no como circunscrito a su aspecto físico exterior, sino como todo el conjunto de su organismo: sus cuerdas vocales, cerebro, esqueleto, etc.

10 Es seguro que le abonará a Shakira, pero que esos ingresos los comparta con su compañía depende de si la discográfica firmó con ella un contrato de los llamados de $360^{\circ}$, en la cual la estrella debe pagar un porcentaje de las ganancias percibidas por todos los productos que contengan su imagen o marca. $\mathrm{Si}$ los comparte, se trataría de una cesión de derechos previamente retribuida (Byrne, 2012, p.220).

11 Recordemos que para Marx la plusganancias se producen cuando los capitalistas venden mercancías que «se producen o cuyo capital funciona en condiciones excepcionalmente favorables, condiciones situadas por encima del nivel medio imperante en esa esfera» (Marx, 2010, pp. 824-825). 
12 El modo de producción asiático también es conocido como despotismo hidráulico. En este modo de producción pese a no existir todavía la propiedad privada, la clase dirigente compuesta de gobernadores y sacerdotes extraían el excedente a los campesinos comunitarios mediante el control privilegiado de la maquinaria estatal. Se produjo allí donde fue necesario construir grandes obras de regadío que solo el Estado podía realizar (Eagleton, 2011, p. 197, Harman, 2013, p. 36 y Manzanera Salavert, 2015, p. 102). 13 Término medio, no le costará lo mismo al hijo de un diplomático aprender idiomas que al de un campesino — capital cultural—, del mismo modo que la hija de un alcalde tendrá más facilidades para obtener un puesto en una empresa que trabaje con el ayuntamiento que la hija de un maestro de escuela - capital social-.

14 Excepto en el caso de enfermedades que imposibiliten el desempeño del puesto de trabajo.

15 La cirugía estética también parte y encuentra su límite en la herencia genética, ya que hasta el momento, no puede hacer «cualquier cosa con cualquier cuerpo».

16 Cuestión para la cual, la relación entre oferta y demanda será crucial, del mismo modo que en el caso de la renta de la tierra. Si no hay necesidad de más estrellas del pop, muchos músicos con potencialidades para convertirse en ellas, quedarán para siempre relegados como asalariados de la industria o pequeños productores directos. Este segundo tipo de trabajadores, intercambien sus actuaciones por dinero, sin consumo capitalista productivo de por medio (Marx, 2009, p. 88).

17 Las excepciones - como Adele o Rosa López - solo confirman la regla —además de que ambas tuvieron que reducir dramáticamente su peso inicial por la industria-. Y pese a sus casos, hay límites físicos que en la industria no se pueden sobrepasar bajo ningún concepto, por ejemplo: no aparecerá absolutamente nadie con obesidad mórbida o con discapacidad evidente por muy buena voz que tenga. 18 Esta predilección por la herencia genética «mejor» se observa incluso en las profesiones más comunes del modo de producción capitalista. Por ejemplo, siempre que la intervención estatal no lo regule, el empresario preferirá un trabajador sano a un trabajador con una enfermedad crónica o una deformidad heredada puesto que el primero, a igualdad del resto de atributos, le hará ganar TTSN y el segundo se lo hará perder en relación con la valorización de su producción mercantil.

19 La sociedad actual, mediante su superestructura legal, coloca impedimentos para este dominio individual sobre la propia capacidad reproductora de vida — diferentes clausulas o imposibilidad total de abortar- y/o la de finiquitar la vida — penalización de la eutanasia-.

20 En determinados contratos llamados de $360^{\circ}$ porque la discográfica se queda con todos los derechos de imagen del artista, pareciera que éste no percibe ninguna remuneración por los derechos de explotación de su imagen. Sin embargo, el artista los percibe por adelantado cuando negocia el precio de su cesión de derechos de imagen a la discográfica, es decir, su cesión del derecho a cobrar una renta diferencial en base a la propiedad monopólica de su propio cuerpo.

21 Siempre, claro está, que haya empresarios que quieran seguir invirtiendo en su «marca», es decir, que deseen continuar produciendo mercancías con representaciones públicamente reconocidas de su cuerpo. Evidentemente, a medida que su anterior público de masas vaya envejeciendo o muriendo, desaparecerá paulatinamente del imaginario colectivo.

22 A veces, los cantantes no componen el tema, pero si tienen suficiente poder, pueden presionar a los compositores para compartir una autoría ficticia que les dé acceso a parte de las regalías. La cantante y compositora Shontelle Layne que ha escrito éxitos para estrellas como Rihanna afirma: «Si estás empezando y tienes la oportunidad de escribir para un artista muy conocido, puede que el contrato del artista con su sello discográfico especifique que tienen derecho a un porcentaje de los ingresos derivados de la publicación de la canción. Algunos artistas fonográficos son lo suficientemente importantes como para poder hacer esto. Te dices a ti mismo: "Si no lo acepto, pierdo esta oportunidad y no cantarán mi canción y no se dará a conocer mi nombre". Yo he pasado por eso. Me gustaría que hubiese una forma de parar esto, pero en este momento no hay nada que puedan hacer al respecto los compositores o los músicos que están empezando» (Samuel, 2011, p. 23). 


\section{REFERENCIAS}

Arrizabalo, X. (2014). Capitalismo y economía mundial. Madrid, España: Instituto Marxista de Economía, ARCIS y UdeC.

Astarita, R. (2009). Monopolio, imperialismo e intercambio desigual. Madrid, España: Maia.

Astarita, R. (2014, abril 14). Teorías del valor: austríacos vs. marxistas (IV parte). Rolando Astarita Blog. Recuperado de https://rolandoastarita.blog/2014/o4/17/teorias-del-valor-austriacos -vs-marxistas-4/

Bourdieu, P. (2001 [200o]). Poder, derecho y clases sociales. Bilbao, España: Desclée.

Brant, E. (2013, septiembre 26). Rihanna wins permanent ban on Topshop selling T-shirt. $B B C$. Recuperado de http://www.bbc.co.uk/newsbeat/article/24282079 rihanna-wins-permanent -ban-on-topshop-selling-t-shirt

Byrne, D. (2012). How music works. Edinburg, usa: Canongate Books.

Eagleton, T. (2011). Por qué Marx tenía razón. Barcelona, España: Península.

Garbulsky, J. (2016, septiembre 16). Puig lanza al mercado la nueva fragancia de Shakira. Masarik Tv. Recuperado de https://masaryk.tv/205624/puig-lanza-al-mercado-la-nueva-fragancia-de-shakira

García Aristegui, D. (2014). ¿Por qué Marx no habló de copyright?: la propiedad intelectual y sus revoluciones. Madrid, España: Enclave de Libros.

Gramsci, A. (200o [1975]). Cuadernos de la cárcel. México DF, México: Era.

Guerrero, D. (1990). Cuestiones polémicas en torno a la teoría marxista del trabajo productivo. Política y Sociedad, 5, 119-130.

Guerrero, D. (2009a). Economía y filosofía en El capital de Marx: la teoría laboral del valor. Filosofía, economía y política en el Laberinto, 29, 51-69.

Guerrero, D. (2009b [2008]). Un resumen completo de El capital de Marx. Madrid, España: Maia.

Harman, C. (2013 [1999]). Historia mundial del pueblo. Desde la Edad de Piedra hasta el nuevo milenio. Madrid, España: Akal.

Horkheimer, M. y Adorno, T. (2009 [1969, 1944]). Dialéctica de la Ilustración. Madrid, España: Trotta.

Husson, M. (2007). Leer El capital hoy. En G. Deville, El capital (Resumido por Gabriel Deville). Barcelona, España: Los Libros de la Frontera.

Jefferson, C. (2010, junio 7). The music industry's funny money. The Root. Recuperado de https://www. theroot.com/the-music-industrys-funny-money-1790880o88

Illescas, J. E. (2014). Industrias culturales y juventud en el sistema-mundo. El videoclip mainstream como mercancía y como reproductor de ideología. (Tesis doctoral). Universidad de Alicante. Alicante, España.

Illescas, J. E. (2016 [2015]). La dictadura del videoclip. Industria musical y sueños prefabricados. Barcelona, España: El Viejo Topo.

International Federation of the Phonographic Industry (IFPI) (2012). Investign in music. How music companies discover, nurture and promote talent. London, UK: IFPI.

Kelley, N. (2002). Rhythm and business. The political economy of black music. New York, UsA: Akashic Books.

Lamelas, M. (24 de abril 2017). Puig coge carrerilla y su beneficio se dispara un 23\% en 2016 . El Confidencial. Recuperado de https://www.elconfidencial.com/empresas/2017-04-24/ puig-resultados-beneficio-karlie-kloss_1371697/ 
Manzanera Salavert, M. (2015). Atravesando el desierto. Balance y perspectivas del marxismo en el siglo xxi. Barcelona, España: El Viejo Topo.

Marx, K. (2009). El capital. Libro I Capítulo vi. Resultados del proceso inmediato de producción. México DF, México: Siglo xxI.

Marx, K. (2010 [1872]). El capital (3 tomos, 8 volúmenes). Madrid, España: Siglo xxI.

National Aeronautics and Space Administration (NASA) (2014). Astronaut Candidate Program. NASA. Recuperado de https://astronauts.nasa.gov/content/brochoo.htm

Passman, D. S. (2012). All You Need to Know About the Music Business. New York, USA: Simon \& Schuster.

Robertson, J. (31 de julio de 2013). Rihanna wins High Court Battle Court against Topshop in '\$5MILLION lawsuit' for using her image without permission. Mirror. Recuperado de https://www.mirror.co.uk/3am/celebrity-news/rihanna-wins-lawsuit-court-battle-2107594

Samuel, S. (2011). Sin compositor no hay canción. Organización Mundial de la Propiedad Intelectual, 5 , 22-24.

Schwartz, L. M. (2007). Making music videos: everything you need to know from the best in the business. New York, UsA: Billboard Books.

Sherwin, A. (19 de agosto de 2014). Justin Bieber and Taylor Swift put stink on Arden's celebrity perfumes. The Independent. Recuperado de http://www.independent.co.uk/news/business/news/justin-bieber-and-taylor-swift-put-stink-on-ardens-celebrity-perfumes-9679107.html

Smith, S. (2015, abril 2). 10 most expensive celebrity parts ever insured: The curious logic behind singers insuring their legs for millions. Ashburnham Insurance Services. Recuperado de https://www.ashburnham-insurance.co.uk/blog/2015/o4/10-most-expensive-celebrity-body-parts-ever-insured/ unesco (2010). Políticas para la creatividad. Guía para el desarrollo de las industrias culturales y creativas. París, Francia: unesco. 